\title{
Information Extraction Method of Soil Salinity in Typical Areas of the Yellow River Delta Based on Landsat Imagery
}

\author{
Tongrui Zhang, Gengxing Zhao*, Chunyan Chang, Zhuoran Wang, Ping Li, Deyu An, \\ Jichao Jia \\ College of Resources and Environment, National Engineering Laboratory for Efficient Utilization of Soil and \\ Fertilizer Resources, Shandong Agricultural University, Tai'an, China \\ Email: zhangtr0924@163.com
}

Received 17 December 2014; accepted 25 December 2014; published 14 January 2015

Copyright (C) 2015 by authors and Scientific Research Publishing Inc.

This work is licensed under the Creative Commons Attribution International License (CC BY). http://creativecommons.org/licenses/by/4.0/

(c) (i) Open Access

\begin{abstract}
In order to get RS method to extract soil salinity of the Yellow River Delta, we set Kenli County as typical Yellow River Delta to be research area and get data of soil salinity through field investigation. By using RS image of Landsat-8 of March 14, 2014 and analyzing information features of each band and surface spectral features of research areas, we select out sensitive bands and build Soil Salinity Information Extraction (SSIE) model and vegetation index NDVI model for comparison. And then, we accordingly classify grades of soil salinity and get soil salinity information by decision tree approach based on expert knowledge. The results show that overall accuracy of SSIE model is $93.04 \%$ and coefficient of Kappa is 0.7869 , while overall accuracy of NDVI model is $83.67 \%$ and coefficient of Kappa is 0.7017 respectively. By comparing with measured proportions of each class, we see that results from SSIE model is more accurate, which indicates significant advantage for soil salinity information extraction. This research provides scientific basis to get and monitoring soil salinity of the Yellow River Delta region quickly and accurately.
\end{abstract}

\section{Keywords}

The Yellow River Delta, Landsat Imagery, SSIE Model, NDVI, Soil Salinity

\section{Introduction}

Soil salinization and alkalization is a globally ecological and environmental issue [1]-[4]. Soil saline is both a

\footnotetext{
*Corresponding author.
}

How to cite this paper: Zhang, T.R., Zhao, G.X., Chang, C.Y., Wang, Z.R., Li, P., An, D.Y. and Jia, J.C. (2015) Information Extraction Method of Soil Salinity in Typical Areas of the Yellow River Delta Based on Landsat Imagery. Agricultural Sciences, 6, 71-77. http://dx.doi.org/10.4236/as.2015.61006 
widely scattered resource and primary environmental disaster. Saline soil can not only arouse soil hardness and fertility decline, but also cause resources destruction and losses in agricultural production, which seriously threaten biosphere and ecological environment [5]-[8].

Detection, monitoring and mapping of soil salinization is a complex work. RS technology, which has features of macrography, comprehensiveness, dynamic and speediness, can get information on same area repeatedly and extensively. It has become a new detection means for earth resources survey and environmental monitoring and has been widely applied for research of soil degradation, especially for monitoring and mapping of saline soil ${ }^{[9]}$-[11].

The method of analyzing features of soil salinization and alkalization by RS image, to build quantitative induction model and get soil salinity information has been paid more and more attention to by experts. Among these effective ways, ratio-type model and NDVI model are two most commonly used methods. R. S. Dwivedi [9] uses PCA, IHS, image difference and ratio methods to study the dynamic changes of the saline-alkali land; Meng Yan [12] extracts the saline land degradation information by analysis the spectral characteristics of the main land types and build saline degradation index; E. N. Bu [13] determines the extent of land salinization through the intensive study of the vegetation types, distribution and colony in northeastern Australia; Han Hui, Feng Zhaogdong et al. [14] extract the information of TM remote sensing images of four different years and analysis different levels of salinization land area during different periods by combination of vegetation index, ground temperature and visual interpretation of land use map. Wu Zhifen and Zhao Shanlun [15] studied the correlation of the Yellow River delta saline vegetation and soil salinity by testing the plants, soil and water samples. It suggested that the saline vegetation types, spatial distribution, intensity of the chemical content of the plant, biological accumulation and succession had close relations with the soil salt content. Zhang Chengwen et al. [16] use the CBERS-02B multispectral images as the data source. It is found that the BP artificial neural network model performs much better than the multiple linear regression model in inversing soil salinity, especially for heavy saline soil area. Lei Lei et al. [17] find both measured hyperspectral soil salinity monitoring model and HSI image soil salinity inversion model have food accuracy. With the increasing development of remote sensing satellite platforms and band and the continuous improvement of the sensor precision, using new remote sensing data to construct model to extract the soil salt content, and extract the soil salt content research need to be further developed.

This essay plans to use measured data and latest Landsat-8 imagery to build ratio-type SSIE model and NDVI model to extract soil salinity information in typical areas of the Yellow River Delta and then explore feasible and effective RS method for soil salinity extraction. Finally the research provides scientific basis to get and monitoring soil salinity quickly and accurately.

\section{Study Area}

Since Yellow River Delta has late land-forming, high water table and mineral proportion, salt is easy to rise to surface. Besides, water of Yellow River has side leaching. In Spring drought is very serious. Together with such reasons as sea water jacking, soil of this area has high salinization and alkalization which causes sparse vegetation on surface with low cover degree. The ecosystem is fragile.

Kenli County is located at entrance of Yellow River downstream. It is close to Bohai Sea in the east. It is the core and most typical area of Yellow River Delta. The research area is sub-humid monsoon climate of warm temperate zone. In Spring drought causes salt accumulation on surface. For many years, the average precipitation is $600 \mathrm{~mm}$. The average evaporation is $1944 \mathrm{~mm}$. The ratio between evaporation and precipitation reaches up to 3:1. The area is low in terrain and has a high ground water level and mineral proportion. It mainly uses water from Yellow River to develop irrigation agriculture. The terrain is low and flat with a natural gradient between 1/8000 - 1/12,000 m. With the combined action of side leaching of Yellow River of water and infiltration and jacking of sea water, there is serious soil salinization and alkalization and frequent changes. Therefore, it is urgent to find a quick and feasible way to induct soil salinity information.

\section{Data and Methods}

\subsection{Research Data}

\subsubsection{Remote Sensing Date}

The season of Spring is a pre-eminent period for information reflection of soil salinity. Therefore, this research 
will be based on RS image of Landsat-8 on March 14th, 2014 as data resource which has resolution of $30 \mathrm{~m}$. The radiation resolution of Landsat-8 is 16 bit and the quantization interval of grayscale is $0-65,535$ which is well above the quantization interval of 0 - 255 of previous 8bit data. This will have better display on details of spectral information and help a lot to recognize fine signature of surface features.

\subsubsection{None-RS Data}

According to factors of land utilization, soil, landform and vegetation form, we evenly choose 58 sampling points in which shoaly land are not included. The distribution is shown in following Figure 1. The time of collection is from February 26th to March 1st, 2014. Besides, none-RS data with 1:50,000 scale thematic maps such as topographic map, administrative map, present landuse map and pedological map are also collected.

\subsection{Research Methods}

\subsubsection{Preprocessing of Images}

The remote sensing data are preprocessed with the aid of ENVI, a software dealing with remote sensing graphics. Based on topographic map of 1:50,000 scale, we evenly choose 50 ground control points to make geometric correction of images by using quadratic polynomial mode. The error is around 0.5 pixel. We also make correction of atmospheric radiation on TM image of research area based on FLAASH module of ENVI. Together with cutting corrected RS image of administrative division boundary of Kenli County, we get only RS image of research area.

\subsubsection{Selection of Sensitive Bands}

At present, it is usually based on correlation coefficient between band reflectance and soil salinity to choose sensitive bands. This lacks consideration of information features of bands and relations between each band. Therefore, it is difficult to fully reflect relations between soil salinity and bands and cannot get accurate data of soil salinity. Because of this, based on GPS coordinates of 58 sampling points, we first get reflectance of each band of these points from RS image, synthesizing correlation between bands and soil salinity and information features of bands themselves, we build a Band Diagnose Index (BDI) for sensitive bands on soil salinity and select sensitive bands accordingly. The computational formula of BDI $\left(P_{i}\right)$ is as follows,

$$
P_{i}=\sigma_{i} \times R_{i}
$$

$\sigma_{i}$ is the Mean Square Error (MSE) of reflectance value of band $i . R_{i}$ is the correlation coefficient between reflectance value of band $i$ and soil salinity. Based on those above, we adopt formula $P=\frac{P_{i}-P_{\min }}{P_{\max }-P_{\min }} \times 100 \%$ to convert $P_{i}$ into between $(0,100)$. Similarly, we adopt formula $\sigma=\frac{\sigma_{i}-\sigma_{\min }}{\sigma_{\max }-\sigma_{\min }} \times 100 \%$ to convert mean-square error of each band into between $(0,100)$.

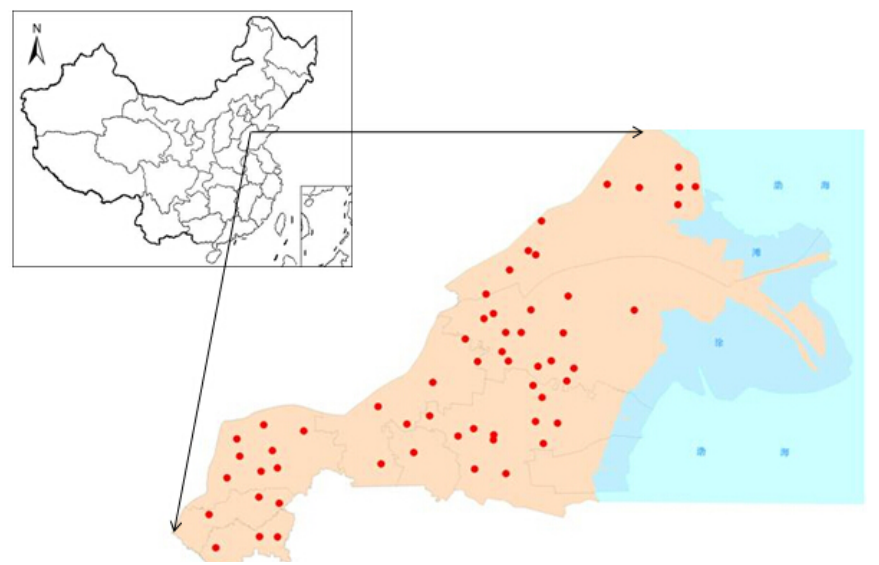

Figure 1. Distribution of samples in the study area. 
Considering information redundancy between each band, in order to get better effect on visual interpretation and maximum reduction of redundancy between bands, we make statistics on basic features of Landsat-8 images and reject bands with high redundancy.

\subsubsection{Building of Spectral Index Model}

According to absorption and reflection of sensitive bands on soil salinity, based on principle that the model makes soil salinity of difference widen, which is good to classify soil salinity of research area, we build ratio-type of spectral index model. Meanwhile, vegetation index NDVI model is also built for comparison.

$$
\text { NDVI }=\frac{\text { NIR }-R}{\text { NIR }+R} \text {, NIR represents grey value of OLI } 5 \text { band (near-infrared), and } R \text { represents grey value of }
$$

OLI 4 band (red of visible light).

\subsubsection{Classification Division of Soil Salinity and Information Extraction}

According to classification standard of soil salinization and alkalization, we divide measured soil salinity of Kenli County into 5 grades. $<1 \%$ is non-saline soil; $<1 \%$ - $<2 \%$ is slightly saline soil; $<2 \%$ - $<4 \%$ is moderately saline soil; $<4 \%$ - $<6 \%$ is serious saline soil. $>6 \%$ is saline soil. Based on relations between image spectral index model and measured soil salinity, we build soil salinity information extraction (SSIE) model and get statistics of soil salinity by image classification.

\section{Results}

\subsection{Results of Sensitive Bands}

\subsubsection{Band Diagnosis Index (BDI)}

Table 1 shows BDI $\left(P_{i}, P\right)$ and Mean Square Error $\left(\sigma_{i}, \sigma\right)$ for each band of Landsat-8. We can see through remote sensing image that BDI and MSE of OLI 5, 6 and 7 on reflectance are distinctly bigger than others'. This indicates that reflectance of OLI 5, 6 and 7 is more sensitive than any other. Therefore, reflectance of these three bands is the best choice to make the inversion research on soil salinity.

\subsubsection{Analysis on Band Redundancy}

Among the RS image, OLI 5 is near-infrared band while OLI 6 and OLI 7 are mid-infrared bands. In the RS image, similar bands have information redundancy. In order to have better visual effect, it is a must to decrease the redundancy as much as possible. Through statistics, these two mid-infrared bands (OLI 6 and OLI 7) have a 0.9807 relativity, which shows that there is a mass of information redundancy between OLI 6 and OLI 7.

\subsubsection{Identification of Sensitive Bands}

Taken together the BDI $\left(P_{6}>P_{7}\right)$, MSE $\left(\sigma_{6}>\sigma_{7}\right)$ and band relativity, in order to minimize the redundancy of band combination to the lowest level, our research chooses near-infrared band OLI 5 and mid-infrared band OLI 6 to build ratio-type soil salinity spectral index model.

\subsection{Results of SSIE Model}

\subsubsection{Model for Image Soil Salinity Spectral Index (SSSI)}

Based on the chosen sensitive bands, there is stronger spectral reflectance within near-infrared band and mid-

Table 1. Diagnostic index and mean square errors for each band of Landsat-8.

\begin{tabular}{ccccccccccc}
\hline Band name & OLI 1 & OLI 2 & OLI 3 & OLI 4 & OLI 5 & OLI 6 & OLI 7 & OLI 8 & OLI 9 \\
\hline$P_{i}$ & 22.50 & 24.36 & 70.21 & 154.44 & 421.97 & 425.90 & 410.19 & 99.45 & 10.28 \\
$P$ & 2.94 & 3.39 & 14.42 & 34.69 & 99.05 & 100 & 96.22 & 21.45 & 1201.32 & 509.97 \\
$\sigma_{i}$ & 250.47 & 312.79 & 451.07 & 689.65 & 1307.11 & 1257.17 & 21.70 \\
$\sigma$ & 17.80 & 22.65 & 33.40 & 51.96 & 100 & 96.11 & 91.77 & 37.99 \\
\hline
\end{tabular}


infrared band on soil salinity. In order to distinguish the soil salinity, this research will build the spectral index model by the differences and sums of OLI 5 and LOI 6 with the maximal radiation quantizing interval of Landsat-8. The Soil Salinity Spectral Index (SSSI) is as follows,

$$
\text { SSSI }=\frac{65535-\text { OLI } 5-\text { OLI } 6}{65535+\text { OLI } 5+\text { OLI } 6} \text {, in which OLI } 5 \text { and OLI } 6 \text { represent reflectance value of OLI } 5 \text { and OLI } 6
$$
respectively.

\subsubsection{Model for Soil salinity Information Extraction (SSIE)}

We establish functional relations by each sampling point SSSI value and NDVI value calculated by SSSI model and measured salt value of corresponding sample point. By this, we build model for soil salinity information extraction (SSIE).

SSIE model based on SSSI is as follows,

$y=122.87 x^{2}-54.409 x+5.6651, R^{2}=0.80$, in which y represents soil salinity and $x$ is SSSI value of sampling point.

SSIE model based on vegetation index NDVI is as follows,

$m=529.32 n^{2}-874.11 n+362.82, R^{2}=0.66$, in which $m$ represents soil salinity and $n$ represents NDVI of sampling point.

\subsection{Result of Soil Salinity Classification}

\subsubsection{Image Grading of Soil Salinity}

Based on classification of soil salinity of field measured data in research area and model for soil salinity information extraction, we make four image grades of soil salinity. According to SSSI, the grades are slight soil salinity (SSSI $<0.355)$, moderate soil salinity $(0.355<$ SSSI $<0.418)$, severe soil salinity $(0.418<$ SSSI $<0.459)$ and saline soil (SSSI $>0.459$ ). According to vegetation index NDVI, the grades are slight soil salinity (NDVI $>$ $0.815)$, moderate soil salinity $(0.762<\mathrm{NDVI}<0.815)$, severe soil salinity $(0.739<\mathrm{NDVI}<0.762)$ and saline soil (NDVI < 0.739).

\subsubsection{Classification Results}

Calculating these two models by software ENVI and classifying the research area by decision tree approach based on professional knowledge, we get distribution maps of soil salinity about the research area of the 2014 . See the following Figure 2.

After taking information statistics and making calculations based on confusion matrix of target area on classified results of images, we get overall accuracy. The SSIE model is $93.04 \%$ while coefficient of Kappa reaches 0.7869. The NDVI model is $83.67 \%$ while coefficient of Kappa reaches 0.7017 . It is seen that the overall accuracy and coefficient of Kappa of SSIE model built in this essay are obviously higher than those of vegetation index model.

Compare the ratio between area of statistics and measured area of soil salinity at each level of the two models, we get Table 2. It shows at each level, the result of SSIE model is much closer to the measured value than that
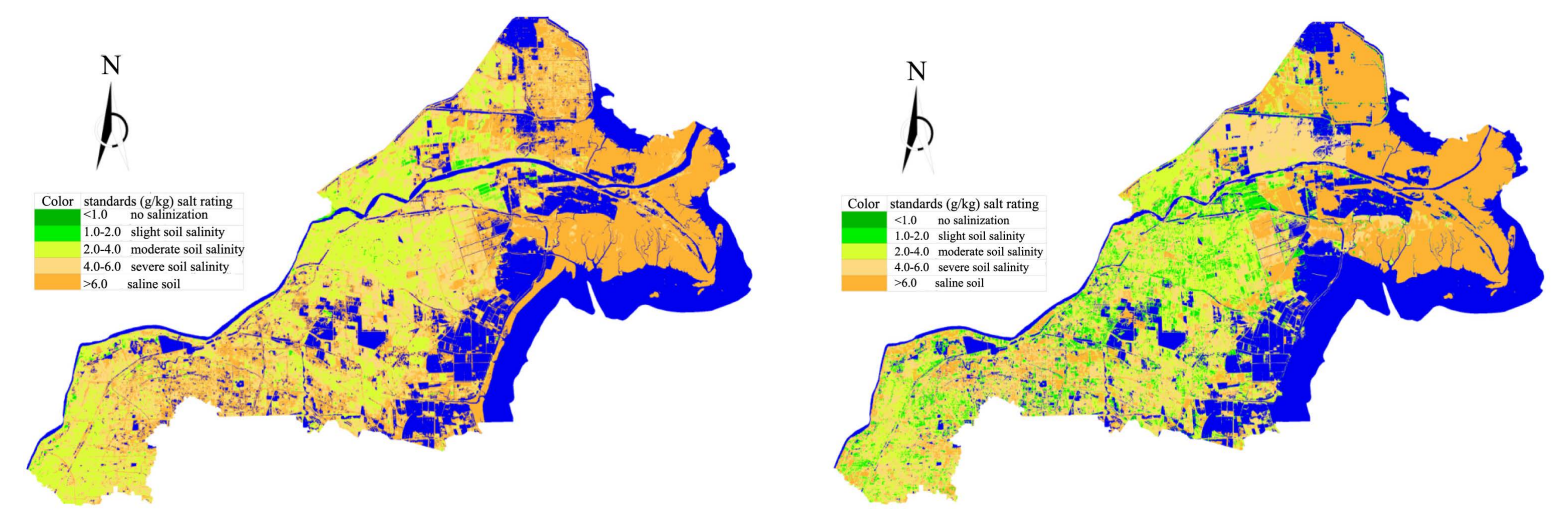

Figure 2. Soil salinity distribution in 2014 of Kenli County (left: SSIE model, right: NDVI model). 
Table 2. Comparison of two extraction model results with the measured values (\%).

\begin{tabular}{cccccc}
\hline & $\begin{array}{c}\text { Slight soil salinity } \\
(\%)\end{array}$ & $\begin{array}{c}\text { Moderate soil salinity } \\
(\%)\end{array}$ & $\begin{array}{c}\text { Severe soil salinity } \\
(\%)\end{array}$ & $\begin{array}{c}\text { Saline soil } \\
(\%)\end{array}$ & $\begin{array}{c}\text { Total } \\
\%)\end{array}$ \\
\hline NDVI model & 9.91 & 28.51 & 27.36 & 34.22 & 100.00 \\
SSIE model & 0.98 & 29.53 & 29.52 & 39.97 & 100.00 \\
Measured value & 0.75 & 33.86 & 24.70 & 40.69 & 100.00 \\
\hline
\end{tabular}

of NDVI model which proves that SSIE model has a distinct advantage on information induction of soil salinity.

\section{Conclusion and Discussion}

1) In this essay, through the analysis of soil salinity and MSE of each band and measured sampling point of Landsat-8, we build the Band Diagnosis Index (BDI) which can measure sensitivity between reflectance of RS image and soil salinity. Meanwhile, considering the relations of each band of Landsat-8, in order to decrease the redundancy between bands, we chose sensitive bands of OLI 5 and OLI 6, which provides an effective method for sensitive band choosing and soil salinity information extraction.

2) This essay builds ratio-type spectral index SSSI model based on OLI 5 and OLI 6 and vegetation index NDVI model based on OLI 4 and OLI 5. According to the measured statistics of soil salinity, we build soil salinity extraction SSIE model and invert soil salinity of research area. After comparing the two results, we find that SSIE model based on SSSI can exactly induct soil salinity of research area, which provides a relatively accurate and fast method for soil salinity information extraction of the Yellow River Delta.

3) In this paper, the red band and near-infrared bands are selected as the most sensitive bands for salinity to establish inversion model. The results are consistent with the results of Yonghua Qu [18], Dwivedi and Rao [19] etc. But the spectral information is complex in research area, same substance with different spectra and same spectra on different substances both exist. Meanwhile, land utilization of this area changes frequently. All these bring difficulty on information induction of soil salinity. There are many delineation of soil among the classification results. Besides, different species of plants vary in saline-alkaline tolerance. These two main reasons result in low accuracy of soil salinity induction from NDVI model based on vegetation index. All these questions have yet to study further.

\section{Acknowledgements}

This study was supported by the "Twelfth Five Year" National Science and Technology Support Project (2013BAD05B06), the National Natural Science Foundation of China (41271235) and the Shandong Independent Innovation Fund (2012CX90202). We gratefully acknowledge support from College of Resources and Environment of Shandong Agricultural University and National Engineering Laboratory for Efficient Utilization of Soil and Fertilizer Resources.

\section{References}

[1] Chen, X.-B., Yang, J.-S. and Hu, S.-J. (2007) Water Resources Development and Control of Soil Secondary Salnization in Yan-Qi Basin. Chinese Journal of Soil Science, 38, 233-237.

[2] Dehaan, R.L. and Taylor, G.R. (2002) Field-Derived Spectra of Salinized Soils and Vegetation as Indicators of Irrigation-Induced Soil Salinization. Remote Sensing of Environment, 80, 406-417. http://dx.doi.org/10.1016/S0034-4257(01)00321-2

[3] Abdellatif, D. and Mourad, L. (2012) Remote Sensing Techniques for Salt Affected Soil Mapping: Application to the Oran Region of Algeria. Procedia Engineering, 33, 188-198. http://dx.doi.org/10.1016/j.proeng.2012.01.1193

[4] Kang, Q., Yu, R. and Zhang, Z.-X. (2005) Advances in Study on Remote Sensing Application of Soil Salinization. Remote Sensing Technology and Application, 20, 447-454.

[5] Ding, J.-L., Wu, M.-C. and Liu, H.-X. (2012)Study on the Soil Salinization Monitoring Based on Synthetical Hyperspectral Index. Spectroscopy and Spectral Analysis, 32, 1918-1922.

[6] Taylor, G.R., Mah, A.H., Kruse, F.A., et al. (1996) Characterization of Saline Soils Using Airborne Radar Imagery. Remote Sensing of Environment, 57, 127-142. http://dx.doi.org/10.1016/0034-4257(95)00239-1 
[7] Weng, Y.L. and Gong, P. (2006) A Review on Remote Sensing Technique for Salt-Affected Soils. Scientia Geographic Sinica, 26, 371-372.

[8] Yang, J.-S. (1995)The Prospect of the Study on Soil Salinization. Soil, 01, 23-27.

[9] Rao, B.R.M., Ravisankar, T., Dwivedi, R.S., et al. (1995)Spectral Behaviour of Salt-Affected Soils. Intemational Joumal of Remote Sensing, 16, 2125-2136. http://dx.doi.org/10.1080/01431169508954546

[10] Li, J.-X., Wang, S.-R.-N. and Bao, Y.-H. (2007) Monitoring Salinification of Land in Zhalot Banner Using Remote Sensing and GIS. Journal of Arid Land Resources and Environment, 21, 57-63.

[11] Khan Nasir, M., Rastoskuev Victor, V., Shalina Elena, V., et al. (2001) Mapping Salt-Affected Soils Using Remote Sensing Indicators-A Simple Approach with the Use of G1S IDRISI. Proceedings ACRS 2001-22nd Asian Conference on Remote Sensing, 1, 25-29.

[12] Meng, Y., Zhao, G.-X. and Wang, J. (2009) Remote Sensing Image-Based Information Extraction for Land Salinized Degradation and Its Evolution in Kenli County. Areal Research and Development, 28, 135-139.

[13] Bui, E.N. and Henderson, B.L. (2003) Vegetation Indicators of Salinity in Northern Queensland. Austral Ecology, 28, 520-560. http://dx.doi.org/10.1046/j.1442-9993.2003.01311.x

[14] Han, H., Feng, Z.-D. and E, Y.-H. (2006) Study on the Saline Soil Changes Using TM in Minqin Oasis, Northwest China. Journal of Lanzhou University, 42, 1-6.

[15] Wu, Z.-F., Zhao, S.-L. and Zhang, X.-L. (1994) Studies on Interrelation between Salt Vegetation and Soil Salinity in the Yellow River Delta. Journal of Plant Ecology, 18, 184-193.

[16] Zhang, C.-W., Tang, J.-K., Yu, X.-J., Wang, C.-L. and Mi, S.-J. (2013) Quantitative Retrieval of Soil Salt Content Based on Remote Sensing in the Yellow River Delta. Journal of Graduate University of Chinese Academy of Sciences, 30, 220-227.

[17] Lei, L., Tiyip, T., Ding, J.-L., Jiang, H.-N. and Kelimu, A. (2014) Study on the Soil Salinization Monitoring Based on Measured Hyperspectral and HSI Data. Spectroscopy and Spectral Analysis, 34, 1948-1953.

[18] Qu, Y.H., Duan, X.L., Gao, H.Y., Chen, A.P., An, Y.Q., Song, J.L., et al. (2009) Quantitative Retrieval of Soil Salinity Using Hyperspectral Data in the Region of Inner Mongolia Hetao Irrigation District. Spectroscopy and Spectral Analysis, 29, 1362-1366.

[19] Dwivedi, R.S. and Rao, B.R.M. (1992) The Selection of the Best Possible Landsat TM Band Combination for Delineating Salt-Affected Soils. International Journal of Remote Sensing, 13, 2051-2058. http://dx.doi.org/10.1080/01431169208904252 
Scientific Research Publishing (SCIRP) is one of the largest Open Access journal publishers. It is currently publishing more than 200 open access, online, peer-reviewed journals covering a wide range of academic disciplines. SCIRP serves the worldwide academic communities and contributes to the progress and application of science with its publication.

Other selected journals from SCIRP are listed as below. Submit your manuscript to us via either submit@scirp.org or Online Submission Portal.
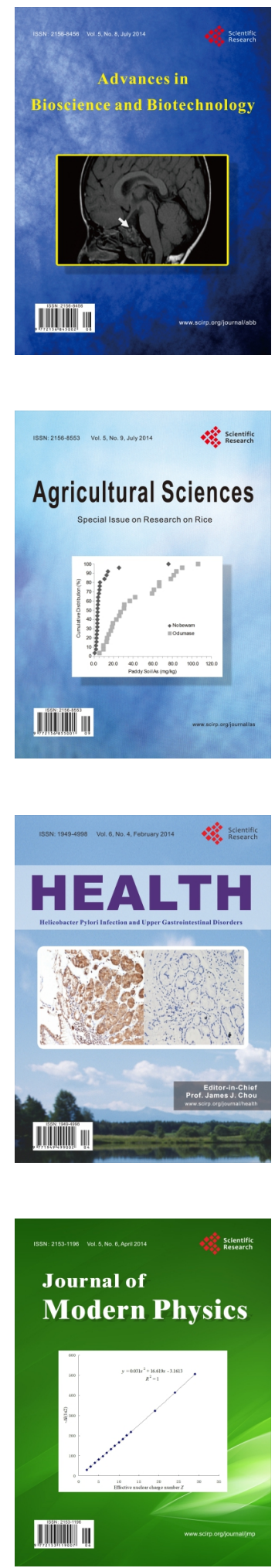
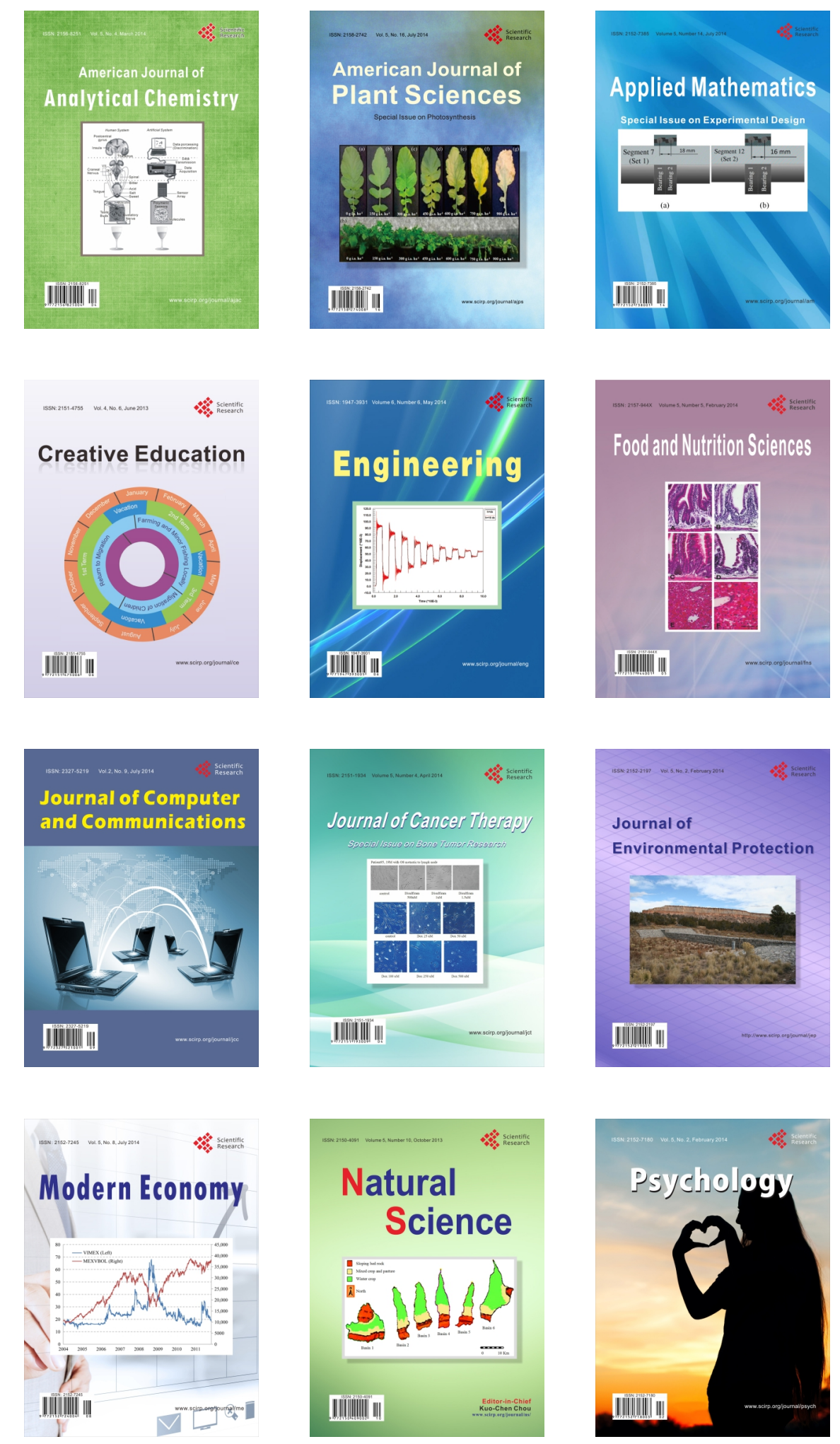